\title{
Finite element analysis of residual stress in the welded zone of a high strength steel
}

\author{
LI YAJIANG*, WANG JUAN, CHEN MAOAI and SHEN XIAOQIN \\ Key Laboratory of Liquid Structure and Heredity of Materials, Ministry of Education, Shandong University, \\ Jinan 250 061, China
}

MS received 30 July 2003

\begin{abstract}
The distribution of the residual stress in the weld joint of HQ130 grade high strength steel was investigated by means of finite element method (FEM) using ANSYS software. Welding was carried out using gas shielded arc welding with a heat input of $16 \mathrm{~kJ} / \mathrm{cm}$. The FEM analysis on the weld joint reveals that there is a stress gradient around the fusion zone of weld joint. The instantaneous residual stress on the weld surface goes up to $800 \sim 1000 \mathrm{MPa}$ and it is $500 \sim 600 \mathrm{MPa}$, below the weld. The stress gradient near the fusion zone is higher than any other location in the surrounding area. This is attributed as one of the significant reasons for the development of cold cracks at the fusion zone in the high strength steel. In order to avoid such welding cracks, the thermal stress in the weld joint has to be minimized by controlling the weld heat input.
\end{abstract}

Keywords. High strength steel; gas shielded arc welding; residual stress; weld cracks.

\section{Introduction}

High strength steels have a great tendency to crack during welding, the reasons being (a) the high hardenability, (b) presence of hydrogen and (c) the stresses present at the weld joint. The determination of critical residual stress that initiates crack during welding has been of interest for quite some time, followed by extensive research work. Several attempts have been made in the past to assess the critical residual stress in the weld zone (Cui and Yi 1985; Chen et al 1987; Tang et al 1988; Michaleris et al 1999; Sun 2000). It is now clear from these investigations that during welding the average stress is not the cause for cracks but an instantaneous stress greater than the average stress at some sensitive region is responsible for the cracking.

This investigation was carried out to study the residual stress in the weld joints of HQ130 steel which is popularly used for high strength and wear resistance applications (Zou and Li 1999; Li et al 2002). Despite the useful properties, this steel is highly amenable to crack formation during welding. With the normally available instrumentation and measuring facilities, it is quite difficult to find out the instantaneous residual stress in the weld zone. Therefore, finite element method (using ANSYS software) was adopted in this work to find out the instantaneous distribution of residual stress. Factors influencing the formation and propagation of weld cracks were analysed and supporting microstructural studies were carried out.

\footnotetext{
*Author for correspondence
}

\section{Experimental}

HQ 130 steel is a low alloy steel, containing small amounts of alloying elements $\mathrm{Cr}, \mathrm{Mo}, \mathrm{Si}, \mathrm{Mn}$ and $\mathrm{Ni}$. The specified value of tensile strength of this steel is $1300 \mathrm{MPa}$ and this steel exhibits correspondingly high hardenability. The chemical composition and mechanical properties of steel after heat treatment (quenching at $920^{\circ} \mathrm{C}$ and tempering at $250^{\circ} \mathrm{C}$ ) are listed below in table 1 .

The microstructure of HQ130 steel contains low carbon, tempered martensite and has a wide range of properties after heat treatment. The width of the weld plate was $150 \mathrm{~mm}$ and the thickness was $12 \mathrm{~mm}$. The test plate was welded using mixed gas shielded arc welding (20\% $\mathrm{Ar}+80 \% \mathrm{CO}_{2}$ gas mixture). Low strength ER100-G filler wire was used for welding (Composition of ER 100-G wire: C 0.07\%, Si 0.45\%, Mn 1.24\%, Mo 0.42\%, $\mathrm{Ni} 1.51 \%$ ). If high strength filler wires are used preheating the weld plate becomes necessary to avoid cracks during welding. But in this case, since ER 100-G was of lower strength, pre-heating of the weld metal was not needed. The welding parameters adopted are given in table 2 .

The weld samples $(75 \times 25 \mathrm{~mm}$, two plates butt joint $)$ were selected based on the relative sample dimensions of "Tekken type cracking test". For ease of experimentation, plain plate sections were used. The thermal field and stress distribution in the weld zone of HQ130 steel were analysed using FEM. The schematic diagram of the weld sample is shown in figure 1 ( $h$ is the thickness of the test plate and $l$ the width). 
Table 1. Chemical composition, mechanical properties and phase transformation temperature of HQ130 steel.

\begin{tabular}{|c|c|c|c|c|c|c|c|c|}
\hline \multicolumn{9}{|c|}{ Chemical composition (weight $\%$ ) } \\
\hline $\mathrm{C}$ & $\mathrm{Si}$ & $\mathrm{Mn}$ & Mo & $\mathrm{Cr}$ & $\mathrm{Ni}$ & $\mathrm{B}$ & $\mathrm{S}$ & $\mathrm{P}$ \\
\hline $0 \cdot 18$ & 0.29 & $1 \cdot 21$ & $0 \cdot 28$ & $0 \cdot 61$ & $0 \cdot 03$ & $0 \cdot 0012$ & $0 \cdot 006$ & $0 \cdot 025$ \\
\hline \multicolumn{9}{|c|}{ Mechanical properties } \\
\hline 1370 & 1313 & & 10 & 43 & & & \multicolumn{2}{|c|}{$64\left(20^{\circ} \mathrm{C}\right)$} \\
\hline \multicolumn{9}{|c|}{ Phase transformation temperature $\left({ }^{\circ} \mathrm{C}\right)$} \\
\hline Acl & Ac3 & & Arl & Ar3 & & & \multicolumn{2}{|c|}{ Austenization } \\
\hline 730 & 850 & & 562 & 754 & & & \multicolumn{2}{|c|}{$920 \pm 10$} \\
\hline
\end{tabular}

Table 2. Welding parameters used in the trials.

\begin{tabular}{lcccc}
\hline Sample & $\begin{array}{c}\text { Welding current } \\
(I(\mathrm{~A}))\end{array}$ & $\begin{array}{c}\text { Welding voltage } \\
(U(\mathrm{~V}))\end{array}$ & $\begin{array}{c}\text { Weld heat input } \\
\left(q / v\left(\mathrm{~kJ} \cdot \mathrm{cm}^{-1}\right)\right)\end{array}$ & $\begin{array}{c}\text { Thickness } \\
(\mathrm{h}(\mathrm{mm}))\end{array}$ \\
\hline 01 & 128 & 30 & $9 \cdot 6$ & 12 \\
02 & 206 & 31 & $16 \cdot 0$ & 12 \\
03 & 280 & 32 & $22 \cdot 3$ & 12 \\
\hline
\end{tabular}

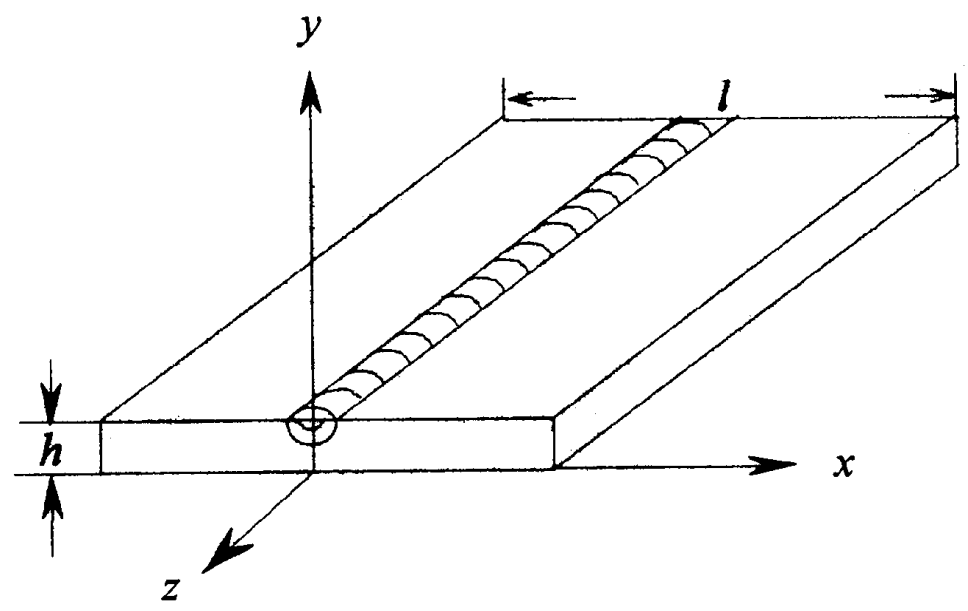

Figure 1. Schematic diagram of the welding test plate.

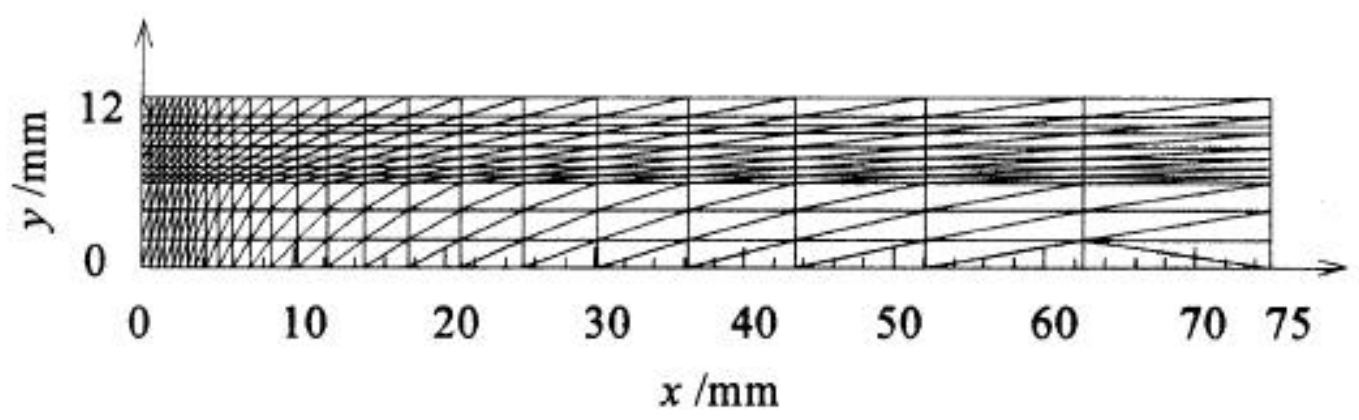

Figure 2. The division of the finite element mesh. 


\section{Program of the finite element calculation}

The finite element analysis of the weld joint consists of two parts: (a) calculation of thermal cycle and (b) calculation of instantaneous stress. A program was drawn up to calculate the thermal cycle. The same program can also be used for the calculation of nonlinear heat conduction in the weld zone. Thermo-physical parameters viz. specific heat, coefficient of thermal conductivity, coefficient of linear expansion and thermal cycle parameters were entered in the program. When end time $t=t_{0}$, the data to determine thermal cycle and thermal field were recorded.

\subsection{The mesh division of the finite element}

Since the weld sample taken for investigation was symmetrical, the symmetry axis was at the weld centre. Exactly half of the weld section was taken for investigation. The sample dimensions and mesh divisions are shown in figure 2. The $x, y$ and $z$ directions represent the width, thickness and length of the sample, respectively. $y=0$ corresponds to the bottom surface of the weld sample and

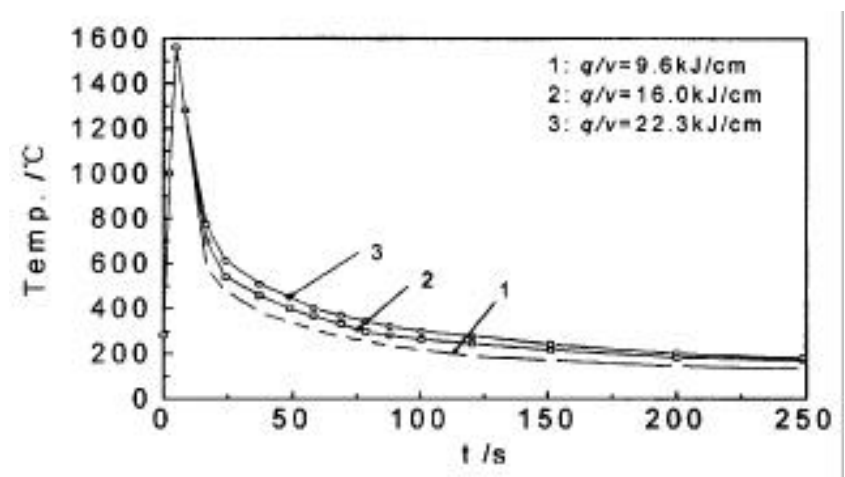

Figure 3. The welding thermal cycles in the fusion zone under different heat inputs. $x=0$ corresponds to the symmetry axis. Because of the non-homogeneity of the weld temperature field and stress field, the weld metal and the heat affected zone (HAZ) were refined locally and the zone farther from the weld metal was coarsened gradually in the mesh division for more accurate results. In the finite element calculations, the heat source acted in the range of $0 \leq x \leq 6 \mathrm{~mm}$ and $6 \leq y \leq 12 \mathrm{~mm}$. The unit taken up for study was triangular, the total units were 480 and the total nodes were 275 .

The thermal cycles of welding in the fusion zone under different heat input conditions are shown in figure 3. Due to the thermal gradient between the sample and the surrounding atmosphere, heat dissipates from the sample to the surrounding by convection and radiation. The total heat exchange coefficient, $\beta$ (a constant $=33.6 \mathrm{~W} / \mathrm{m}^{2} \cdot{ }^{\circ} \mathrm{C}$ ), was used in the calculation.

\subsection{Programming}

The basis of the finite element technique (to tackle the thermal elastic-plastic problem) is to change the nonlinearity relation of the stress and strain into a linear one during the loading process. The external force does not have any effect on welding. But loading is due to the change in temperature. The procedure to tackle this problem is to calculate the increment of the load with change in temperature, $\Delta T$, then add up these to the structural elements. The centre axis was symmetrical and free boundary conditions were assumed. The flow diagram of the program is shown in figure 4.

The finite element analysis of the thermal elastic-plastic stress was conducted using ANSYS software. As a first step, the component was divided into several finite elements. The thermo-physical parameters were entered and the distribution of thermal field of welding was found out. The determination of stress field followed. Using the non-linear instantaneous stress analysis, heat and struc-

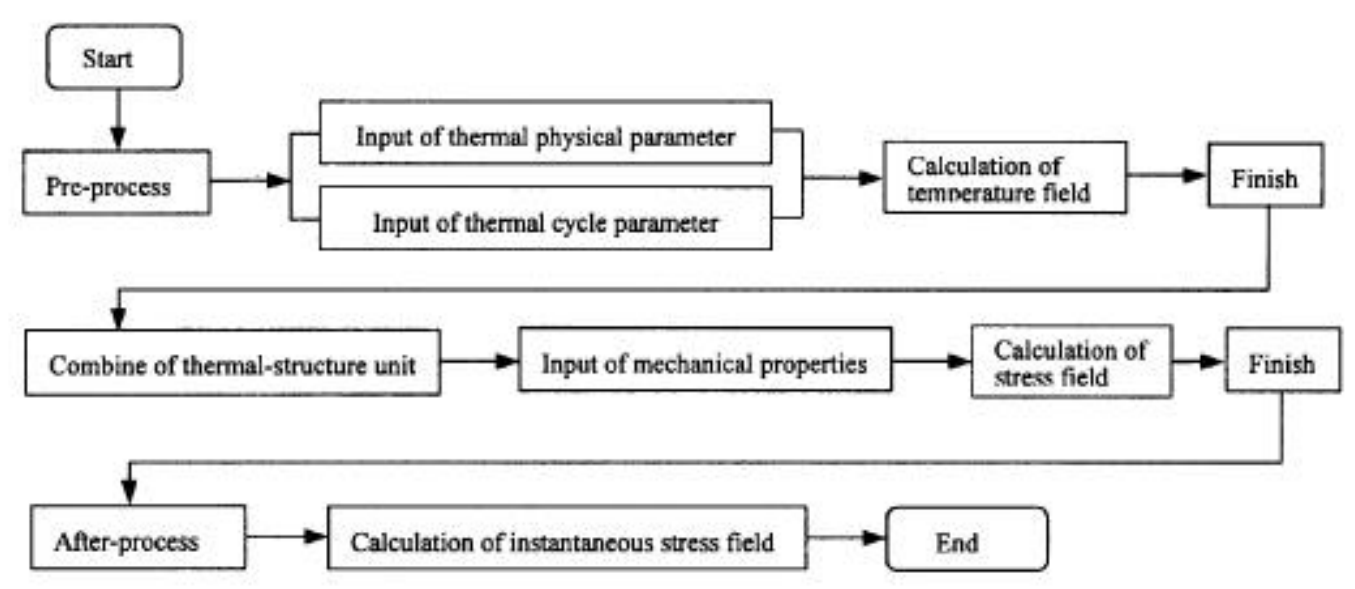

Figure 4. The flow of the finite element analysis of the stress field. 
ture unit were combined in the calculation. The mechanical parameters (elasticity modulus, $E$, tensile strength, $\sigma_{\mathrm{b}}$, Poisson's ratio, $\mu=0 \cdot 3$, coefficient of linear expansion, $\alpha$, shear modulus, $G$, etc) were recorded in the program. Subsequently, the instantaneous residual stress during welding were calculated.

These thermo-physical parameters change with the change in temperature (see figure 5). For the sake of convenience, the parameters such as coefficient of heat con-
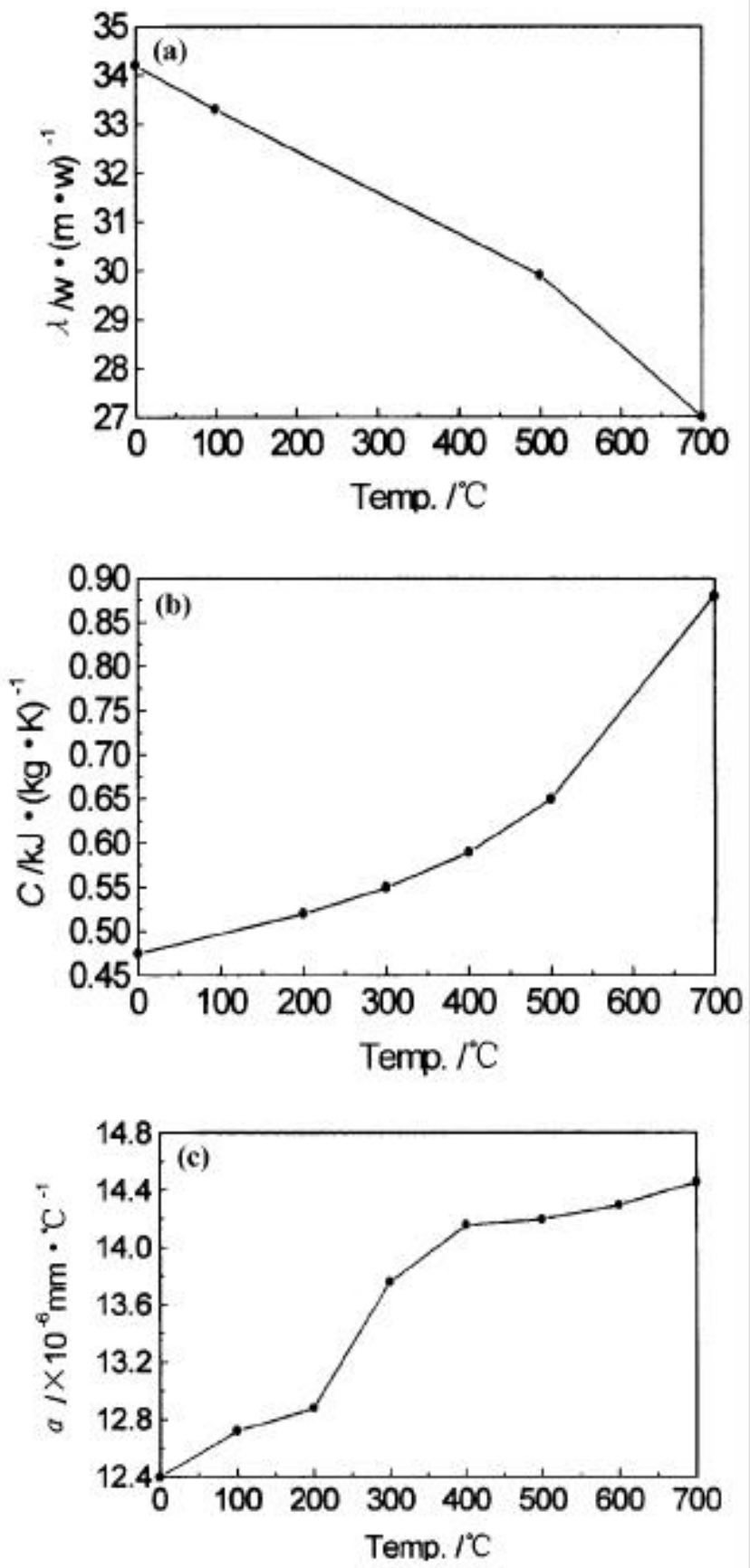

Figure 5. The relationship between thermal physical parameters and temperatures: (a) coefficient of heat conductivity, (b) specific heat and (c) coefficient of linear expansion. ductivity, specific heat, coefficient of linear expansion and density were extrapolated assuming a linear variation with temperature.

\section{Results and discussion}

The test plate of HQ130 steel was welded without any pre-heating, at varying welding heat input and the residual stress in the weld zone corresponding to each situation was analysed. It is known that the stress, $\sigma_{x}$, perpendicular to the weld direction has a strong influence on the cold cracks compared to $\sigma_{y}$ and $\sigma_{z}$ which have much lesser
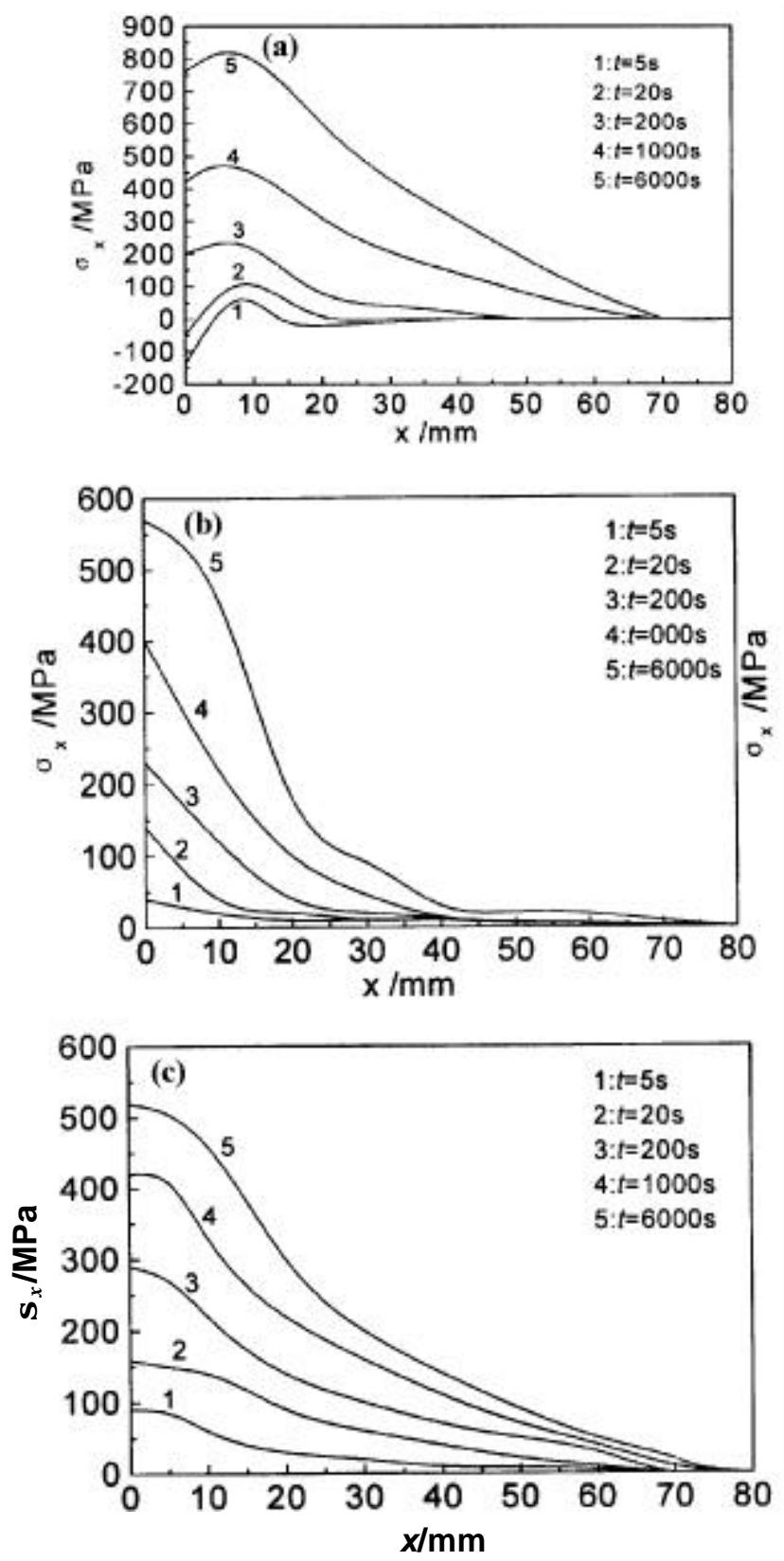

Figure 6. The distribution of stress, $\sigma_{x}$, along $x$ direction in the welding zone. (a) Upper surface, $y=12 \mathrm{~mm}$, (b) bottom of welded metal, $y=6 \mathrm{~mm}$ and (c) bottom of the test plate, $y=0$. 

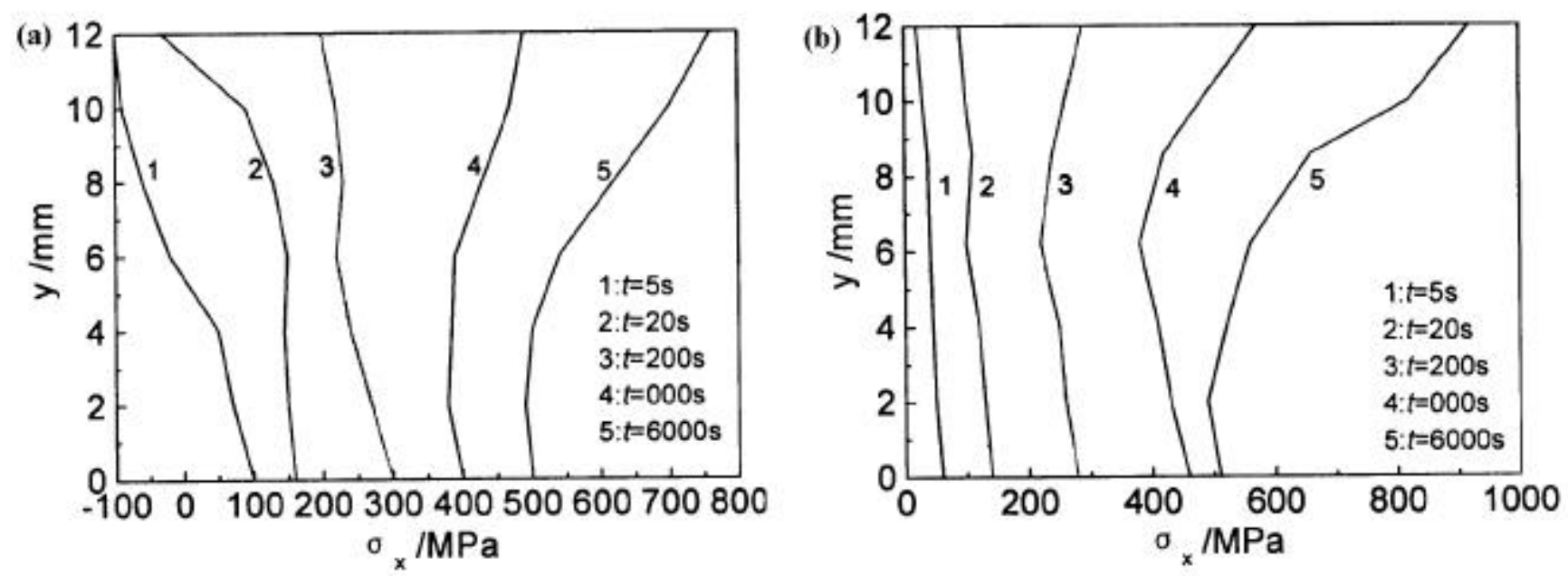

Figure 7. The distribution of the stress, $\sigma_{x}$, along $y$ direction in the welding zone: (a) the centre axis, $x=0$ and (b) the fusion zone, $x=6 \mathrm{~mm}$.

influence. Therefore, importance has been given in this work to the analysis of distribution of stress, $\sigma_{x}$.

The instantaneous stress distribution of $\sigma_{x}$, at various time intervals is shown in figure $6(\mathrm{a}, \mathrm{b}, \mathrm{c})$. At $5 \mathrm{~s}$ after the welding, a compressive stress is present on the surface of the weld metal whereas a tensile stress is present at the HAZ, mainly due to the thermal expansion in the weld zone. The residual stress in the weld zone increases gradually with the increase in time and reaches a peak when $t=6000 \mathrm{~s}$. The residual stress decreases across the test plate and the stress distribution stabilizes gradually.

In the beginning, $\sigma_{z}$ along the thickness of the plate decreases from the surface to the base, due to the thermal expansion and elongation of test plate. As the time progresses, the value of the stress, $\sigma_{z}$, at all locations increases with increase in time. Finally, the weld metal and the fusion zone reach the peak tensile residual stress in $x$ and $z$ directions, whose value is less than the tensile strength of the base metal HQ130 steel. It is to be noted that in butt welding, residual stress is higher due to the concentration of stress.

High strength steel is welded and the initiation of crack is determined by the stress state in the welding zone. The calculated results of the stress distribution in the welding zone indicate that the weld metal and the fusion zone experience compressive stress of little tensile stress at the beginning. But, the stress increases gradually with time. Finally the weld metal and the fusion zone have tensile residual stresses in $x$ and $z$ directions, but their value is less than the ultimate tensile strength of HQ130 steel.

The change and distribution of $\sigma_{x}$ at the centre axis $(x=0)$ and the fusion zone $(x=6 \mathrm{~mm})$ of the test plate along the $y$ direction are shown in figure 7. At the beginning, there is compressive stress at the central axis of the weld metal. However, $\sigma_{x}$ increases gradually with time and finally there is only tensile stress at the central axis, as shown in figure 7 (a). The maximum stress is present at the upper surface of the test plate. At the beginning, the maximum of $\sigma_{x}$ is in the fusion zone $(x=6 \mathrm{~mm})$, but when $\sigma_{x}$ increased gradually, the maximum restrain stress, $\sigma_{x}$ shifts to the upper surface in HAZ near the fusion zone, as shown in figure 7 (b).

Phase boundaries, impurities and micro defects present in the weld metal act as the source for crack formation near the fusion zone. As the stress increases on the weld zone, the above defects originate cracks. New dislocations accumulate around the crack tip and cause stress concentration zones. With the increase in stress, newer cracks form. Thus, the initiation, propagation and fracture in the welding zone of high strength steel are related to the formation and accumulation of instantaneous stress. Therefore, it is important to control the welding heat input to reduce the welding stress and to avoid cracks.

\section{Conclusions}

(I) The distribution of the residual stress in the weld zone of HQ130 steel (welded using Argon/ $\mathrm{CO}_{2}$ welding), was determined using ANSYS finite element software. It is seen that the stress, $\sigma_{x}$, in the direction of the width of test plate has highest influence on the formation of cold cracks.

(II) The experimental results reveal that there is a stress gradient around the fusion zone. The instantaneous stress on the weld surface is $800-1000 \mathrm{MPa}$ and below the weld is 500-600 MPa. This gradient is high near the fusion zone and this is one of the reasons for the formation of cracks in the fusion zone in high strength steels.

\section{Acknowledgements}

The authors gratefully acknowledge the support given by the National Natural Foundation of China (Grant 
no. 50375088) and Shandong Province Natural Science Foundation (Y2003F05).

\section{References}

Chen Chu, Wang Jianhua and Luco Yu 1987 Trans. China Welding Inst. 8196 (in Chinese)

Cui Wenyuan and Yi Chuanbao 1985 Trans. China Welding Inst. 6124 (in Chinese)
Li Yajiang, Zou Zengda, Liu Dezhen and Juan Wang $2002 \mathrm{~J}$. Mater. Sci. Technol. 1821

Michaleris P, Dantzig J and Tortorelli D 1999 Welding J. 78 $361 \mathrm{~s}$

Sun X 2000 Welding J. 79 244s

Tang Moyoa, Ding Shiliang and Meng Fansen 1988 Trans. China Welding Inst. 9125 (in Chinese)

Zou Zengda and Li Yajiang 1999 Chinese J. Mech. Engg. 3570 (in Chinese) 